\title{
Preliminary evidence for an impulsivity-based thrifty eating phenotype
}

\author{
Patrícia P. Silveira', Marilyn Agranonik', Hadeel Faras², André K. Portella', Michael J. Meaney ${ }^{3,4}$, Robert D. Levitan ${ }^{5}$; on behalf of \\ the Maternal Adversity, Vulnerability and Neurodevelopment (MAVAN) Study Team
}

INTRODUCTION: Low birth weight is associated with obesity and an increased risk for metabolic/cardiovascular diseases in later life.

RESULTS: The results of the snack delay test, which encompassed four distinct trials, indicated that the gender $\times$ intrauterine growth restriction (IUGR) $\times$ trial interaction was a predictor of the ability to delay the food reward $(P=0.002)$. Among children with normal birth weights, girls showed a greater ability to delay food rewards than did boys $(P=0.014)$.In contrast, among children with IUGR, there was no such differential ability between girls and boys. Furthermore, in girls, impulsive responding predicted both increased consumption of palatable fat $(P=0.007)$ and higher BMIs $(P=0.020)$ at $48 \mathrm{mo}$ of age, although there was no such association with BMl at 36 mo.

DISCUSSION: In girls, the quality of fetal growth may contribute to impulsive eating, which may promote an increased intake of fats and consequently higher BMls. As with the original thrifty phenotype, such a mechanism would be adaptive when food supplies are sparse, but would be problematic in societies with ample access to calorically rich foods.

METHODS: We examined whether the quality of intrauterine growth programs obesogenic eating behaviors, by investigating (i) the relationship between birth weight and impulsive eating in 3-year-old children (using the snack delay test), and (ii) whether impulsive eating predicts fat intake and/or BMI at 4 years of age (using a laboratory-based test meal).

T he quality of perinatal growth influences health throughout life. Perhaps the best example of this association is the link between intrauterine growth restriction (IUGR) and the metabolic syndrome in adulthood, expressed in terms of insulin resistance $(1,2)$, type 2 diabetes $(1)$, hypertension $(3,4)$, an altered lipid profile $(5,6)$, obesity (7-10), and cardiovascular disease $(11,12)$. The thrifty phenotype hypothesis of Hales and Barker (13) proposes that low birth weight and associated long-term insulin resistance are adaptive if food supplies are scarce and likely to remain so over time. A thrifty phenotype is thought to be triggered by one or more signals of maternal malnutrition passing across the placenta to the developing fetus, providing the fetus with a forecast of a sparse nutritional environment. If the prediction proves inaccurate and food supplies become abundant, the thrifty phenotype becomes a risk factor for obesity, diabetes, and cardiovascular disease.

Although the thrifty phenotype hypothesis focuses on programming of metabolism during fetal development, it is entirely plausible that obesogenic patterns of eating behavior per se are also programmed by early fetal adversity and low birth weights. In support of this hypothesis, we found that young adult women who have experienced IUGR prefer carbohydrates over protein and have larger waist-to-hip ratios, despite having no signs of insulin resistance or diabetes mellitus (14). Other research groups report that there are specific food preferences among individuals exposed to nutritional shortage during gestation, manifesting as intake of high-fat diets (15) and higher energy intake (16) in late middle age. Eating habits associate with obesity, diabetes, and cardiovascular disease (17-20). Therefore, in individuals who had experienced IUGR, the persistence of small energy imbalances across the life span could explain, at least in part, the increased risk of developing metabolic diseases in later life.

Although the finding of a link between IUGR in infancy and food preferences in adulthood is of great interest, the direction of causality in this relationship is unclear. It may be that IUGR triggers adaptive metabolic changes that secondarily influence eating behavior over time. One way to test the hypothesis that IUGR in itself programs eating behavior, independent of metabolism, is to study this putative phenomenon very early in life, before metabolic changes are likely to manifest themselves. However, no such studies have been published to date.

Our study tests a novel variation of the thrifty phenotype hypothesis, that we refer to as the "thrifty eating hypothesis." We propose that, in many cases, fetal stress and IUGR establish sustained changes in brain mechanisms that regulate eating behavior. Such changes might be highly adaptive when food supplies are low. However, as with the original thrifty hypothesis, these behaviors become a risk factor for obesity, diabetes, and the metabolic syndrome in a food-abundant environment.

\footnotetext{
'Núcleo de Estudos da Saúde da Criança e do Adolescente, Faculdade de Medicina, Universidade Federal do Rio Grande do Sul, Porto Alegre, Brazil; ${ }^{2}$ Developmental Pediatric Unit, Department of Pediatrics, Al Sabah Hospital, Safat, Kuwait; ${ }^{3}$ Department of Psychiatry and Neurology, McGill University, Montreal, Quèbec, Canada; ${ }^{4}$ Singapore Institute for Clinical Sciences, Singapore; ${ }^{5}$ Department of Psychiatry, University of Toronto and Centre for Addiction and Mental Health, Toronto, Ontario, Canada. Correspondence: Patrícia P. Silveira (00032386@ufrgs.br)
} 
Impulsive eating is an excellent example of a behavior that would be adaptive when food supplies are scarce, but highly obesogenic in an environment with abundant availability of high caloric foods. We therefore investigated the possible association between IUGR and impulsive eating, using a snack delay task in 3-year-old Canadian children. Based on our previous findings (14), our first hypothesis was that a history of IUGR would be associated with impulsive response toward a palatable snack at the age of $36 \mathrm{mo}$, particularly in girls. Our second hypothesis was that impulsive eating at 36 mo would predict the quantum of intake of palatable fat (hypothesis 2a) and/or higher BMIs (hypothesis $2 \mathrm{~b}$ ) at the age of $48 \mathrm{mo}$.

\section{RESULTS}

Table 1 depicts the baseline characteristics of the subjects who experienced IUGR and those who did not. There were no statistically significant differences between these two groups of children as regards gender, smoking of the mother during pregnancy, age of the mother at the time of delivery, the duration of exclusive breastfeeding, or the total duration of breastfeeding up to 12 mo of age (Table 1). There was also no statistical difference between the two groups with regard to BMI at 36 and 48 mo of age.

Analysis of the snack delay data revealed a significant threeway interaction among gender, IUGR, and trial number in predicting total performance scores $(P=0.002$, Table 2). Post hoc analysis (least significant difference) revealed that, among children with normal birth weights, girls had a significantly greater ability than boys to delay responding to eating impulse, across the trials $(P=0.014)$. In contrast, among children with a history of IUGR, girls and boys behaved similarly across the four trials $(P=0.317)$. This suggests that the experience of IUGR negates the superior ability of girls to delay their response to the eating impulse.

\section{Snack Delay Data at $36 \mathrm{mo}$ as Predictor of Quantum of Fat Intake at $48 \mathrm{mo}$ :}

The mean response delay scores across all four trials in 36mo-olds were negatively correlated with the amount $(\mathrm{g})$ of fat derived from palatable foods (muffin, croissant, and Frosted Flakes) consumed during the structured lab meal test 12 mo later at the age of $48 \mathrm{mo}$, but only in girls $(B=-0.956 ; P=$ $0.007 ; n=37)$. There was no such effects in boys $(B=0.149 ; P=$ $0.149 ; n=33)$. This relation remained significant in girls even after adjusting for 48-mo BMI $(B=-0.751 ; P=0.037)$.

\section{Snack Delay Score at $\mathbf{3 6}$ mo as a Predictor of BMI Values at 36 and 48 mo:}

As shown in Table 3, the mean of the snack delay test score at the age of 36 mo was not significantly associated with the BMI at the same age, in either boys or girls. In contrast, in girls alone, the mean snack delay score at the age of 36 mo was a significant predictor of the BMI at $48 \mathrm{mo}\left(r^{2}=0.115, P=\right.$ 0.026). The results further indicated that each increase of 1 unit in the average snack delay score at the age of 36 mo (reflecting less impulsive behavior) was associated with a $0.613 \mathrm{~kg} / \mathrm{m}^{2}$ decrement in BMI at $48 \mathrm{mo}$. The addition of birth weight ratio (BWR) to the model (Model 2) did not significantly affect this association.

Taken together, analyses of data with respect to hypotheses $2 \mathrm{a}$ and $2 \mathrm{~b}$ suggest that girls who showed a greater ability to delay responding during the snack delay task at the age of 36 mo exhibited both lower fat intake and lower BMIs at the age of $48 \mathrm{mo}$.

\section{DISCUSSION}

In this study we found that, over all four trials, girls with normal birth weights had significantly greater ability to delay responding to the eating impulse as compared with boys with normal birth weights. In contrast, among children with a history of IUGR, girls did not have enhanced ability to delay eating impulse (food reward) relative to boys. Furthermore, in girls alone, eating impulse response scores at the age of 36 mo predicted both quantum of consumption of palatable fat and BMI values at the age of $48 \mathrm{mo}$, despite there being no such association with BMI at $36 \mathrm{mo}$. These data take on added significance in conjunction with the finding that young adult women with a history of IUGR show a preference for carbohydrates (14).

Table 1. Study participants' baseline characteristics according to presence or absence of IUGR at birth

\begin{tabular}{|c|c|c|c|c|c|}
\hline Sample characteristics & Non-IUGR $(n=125)$ & & $\operatorname{IUGR}(n=35)$ & & $P$ \\
\hline Males (\%) & $68(54.4 \%)$ & & $15(42.9 \%)$ & & $0.25^{\mathrm{a}}$ \\
\hline Maternal age at birth (years) & $30.07 \pm 0.46$ & & $28.44 \pm 0.95$ & & $0.11^{\mathrm{b}}$ \\
\hline Maternal smoking during gestation (\%) & $16(13.2 \%)$ & & $5(14.7 \%)$ & & $0.78^{\mathrm{a}}$ \\
\hline Family income below LICO (\%) & $33(28.4 \%)$ & & $7(21.9 \%)$ & & $0.51^{\mathrm{a}}$ \\
\hline Exclusive breastfeeding (weeks) & $8(0 ; 20)$ & & $7(0 ; 16)$ & & $0.22^{c}$ \\
\hline Total duration of breastfeeding (weeks) & $24(6 ; 48)$ & & $28(8 ; 48)$ & & $0.65^{c}$ \\
\hline $\mathrm{BMI}\left(\mathrm{kg} / \mathrm{m}^{2}\right)$ & Boys & Girls & Boys & Girls & \\
\hline At $36 \mathrm{mo}$ & $16.34 \pm 0.21$ & $16.21 \pm 0.23$ & $15.97 \pm 0.34$ & $16.32 \pm 0.54$ & 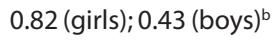 \\
\hline At $48 \mathrm{mo}$ & $16.04 \pm 0.29$ & $15.61 \pm 0.28$ & $15.32 \pm 0.44$ & $16.94 \pm 1.11$ & 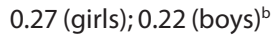 \\
\hline
\end{tabular}

Data are expressed as mean \pm SEM, median (25th percentile; 75 th percentile), or proportions (percentages).

IUGR, intrauterine growth restriction; LICO, low income cut off (48).

${ }^{a} X^{2}$ test. ${ }^{b} S t u d e n t ' s t$-test. Mann-Whitney test. 
Table 2. Mean performance on the snack delay task across the four trials

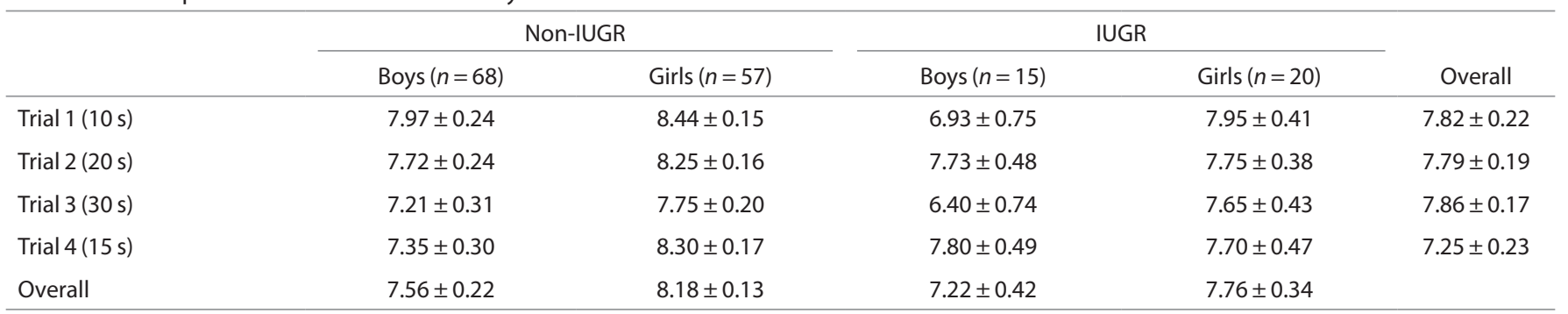

Performance = arithmetic sum of the observer-rated snack delay behavior score (range 1-7) and the observer-rated latency to eat score (range 1-2). The possible range of scores on any one trial is thus 2 (highly impulsive) to 9 (highly restrained). Each of the four trials was of different duration as shown in the brackets next to each trial number. Data are expressed as mean \pm SEM.

Table 3. Hierarchical linear regression models predicting BMI at 36 or 48 mo of age with 36-mo snack delay scores, stratified by sex

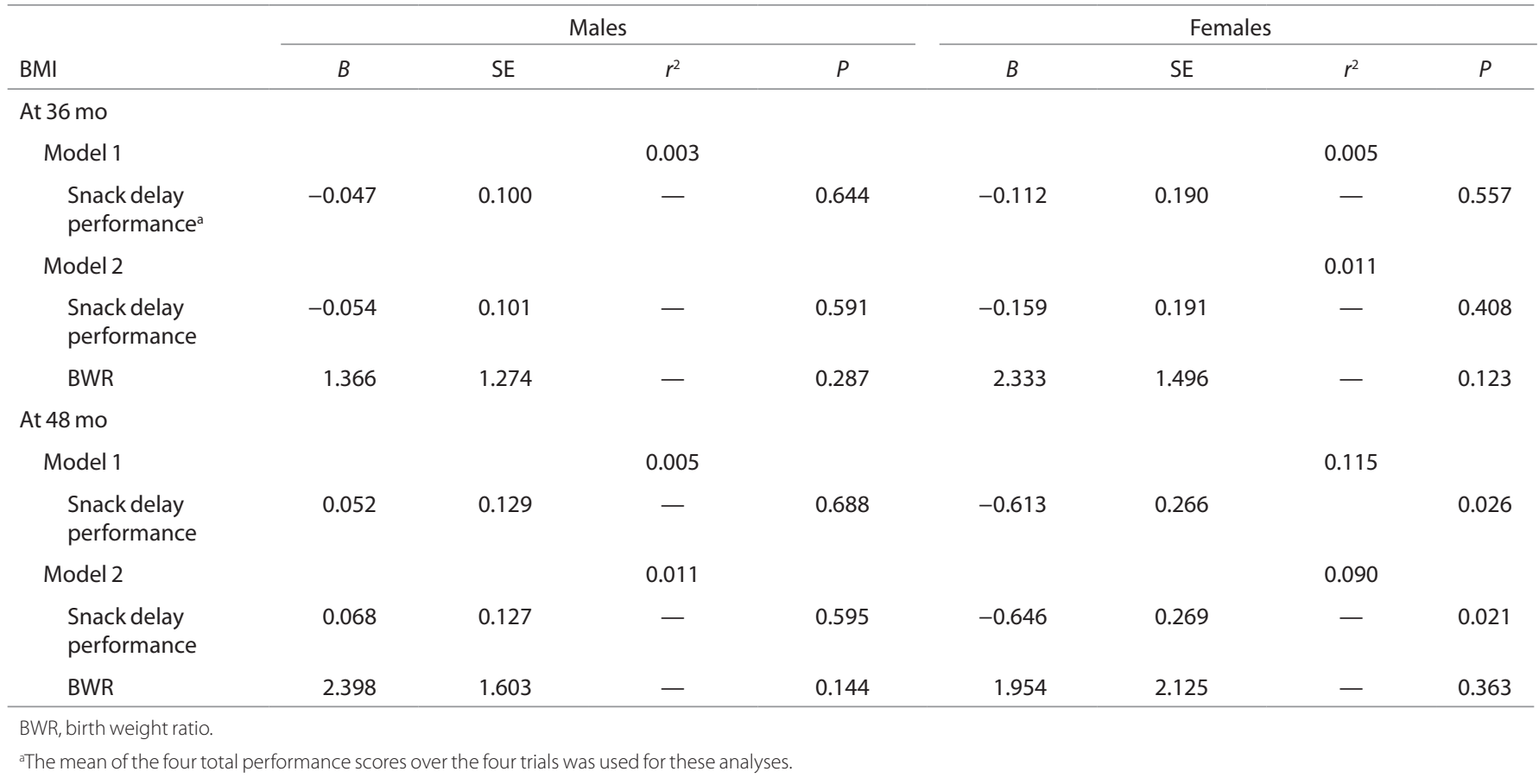

Other studies have shown that undernutrition at the fetal stage is associated with increased ingestion of fats at a later stage in life (15), and increased total energy intake (16) in late middle age. However, the results of these prior studies could be attributable to secondary effects of IUGR-induced metabolic changes on food choices. Given the young age of our study probands, our study suggests, for the first time, that IUGR is associated with obesogenic changes in eating behavior, and that these changes are unlikely to be secondary to metabolic effects. Indeed, our study results raise the possibility that, in many cases, high-risk eating behavior may promote the metabolic changes previously attributed directly to IUGR.

Another consideration in interpreting our results in female subjects is that fetal stress may program parallel changes in food intake and insulin resistance $(21,22)$ at the same time. Perinatal growth has been shown to be associated with altered methylation of a pro-opiomelanocortin promoter in the hypothalamus in mice (23). This developmentally regulated epigenetic state results in stable changes in pro-opiomelanocortin expression and appetite (23). Whether the insulin resistance and perinatal programming of appetite are two entirely distinct phenomena, or whether they reflect different manifestations of a broader "thrifty phenotype" is an issue requiring further study.

Our study suggests that increase in impulsive eating may link IUGR and food preferences in girls. Functional magnetic resonance imaging studies show that the decision to favor a long-term goal vs. an immediate reward relies on functional interactions between the prefrontal cortex and the nucleus accumbens and ventral tegmental area; the intensity of this functional interaction correlates with interindividual differences in trait impulsivity (24). Impulsive personality traits are also related to executive functioning (25). It is interesting to note that infants who experience undernutrition during fetal life have poorer executive functioning $(26,27)$ and increased vulnerability to addictive disorders (28) and to attention deficit hyperactivity disorder (29). Recent studies demonstrate substantial links between attention deficit hyperactivity disorder and obesity/overweight (30), and suggest that obesity may be seen as the sign of an addictive disorder (31). 
The small sample size was a limitation of our study. However, considering that the Maternal Adversity, Vulnerability and Neurodevelopment (MAVAN) subjects represent an ongoing prospective cohort, we may be able to explore these findings further in future studies. Our study has some strengths: by using a behavioral task instead of a questionnaire to measure eating impulsivity, we were able to measure an actual behavioral trait that correlates with a real difference in preferences during eating behavior, as observed on the snack test applied at 48 mo. We do not know whether this altered preference shown by the girls in our study will lead to obesity in the long term or not; however, the preference for palatable foods rich in fat may be a risk factor for the development of overweight and obesity.

Although the ages of the subjects in the sample suggest that IUGR may program feeding behavior in a manner that is independent of metabolism, the link between eating behavior and metabolism in these individuals is likely to become more complex over time. For example, it has been proposed that glucocorticoids and insulin stimulate the consumption of highly calorie-dense foods ("comfort foods"), which, in turn, would protect the hypothalamic-pituitary-adrenal axis from potential dysfunction (32). Individuals with a history of IUGR show an increased adrenal response to acute stress $(33,34)$. These features, combined with the known factor of insulin resistance, would exaggerate earlier tendencies to consume palatable, "comfort" foods over time. Therefore, although our study results suggest that IUGR may have direct effects on feeding behavior early in life, it is expected that the metabolic changes associated with IUGR would also influence food choices over time, further increasing the risk for overweight/obesity, metabolic syndrome, and related disorders in these individuals.

\section{METHODS}

The study sample comprised 3-year-old children from the cities of Montreal, Quebec, and Hamilton, in Ontario, Canada. Participants were recruited from an established prospective birth cohort (the MAVAN project). Eligibility criteria for mothers included age $\geq 18$ $y$, singleton pregnancy, and fluency in French or English. Mothers were excluded from the study if they had severe chronic illness, placenta previa, a history of incompetent cervix, impending delivery, or had a fetus/infant born at gestational age $<35 \mathrm{wk}$ or born with a major anomaly. Birth records were obtained directly from the birthing unit. A total of 215 children participated in the follow-up examination for 3-year-olds, and 162 came to the study laboratory for the snack delay test. Two children were excluded from the analysis based on having a global co-operation score of lower than 2, meaning that they could not cooperate in the task (explained later in this paper). There was no significant difference between the children included and excluded with respect to history of IUGR. Of the 160 subjects evaluated at 36 mo of age, 82 returned at 48 mo of age for a laboratory-based evaluation of food preferences, by means of a structured meal (explained later in this paper), in addition to anthropomorphic measures.

Approval for the MAVAN project was obtained from obstetricians performing deliveries at the study hospitals and by the institutional review boards at hospitals and university affiliates: McGill University, l'Université de Montréal, the Royal Victoria Hospital, Jewish General Hospital, Centre Hospitalier de l'Université de Montréal, Hôpital Maisonneuve-Rosemont, St Joseph's Hospital, and McMaster University, Hamilton, Ontario, Canada. Informed consent was obtained from the parents/guardians of the participants. The definition of IUGR was based on the BWR, namely, the ratio between the birth weight and the sex-specific mean birth weight for each gestational age for the local population. A BWR of $<0.85$ was classified as IUGR (35).

BMI was calculated as weight in kilograms divided by height in meters squared $\left(\mathrm{kg} / \mathrm{m}^{2}\right)$. The height while standing without footwear, was measured (to the nearest $0.1 \mathrm{~cm}$ ) using a stadiometer (PE-AIM-101; Perspective Enterprises, Portage, MI). Body weight, in light clothing, was measured (to the nearest $0.1 \mathrm{~kg}$ ) using a digital floor scale (TANITA BF625; Tanita, Arlington Heights, Illinois).

In the snack delay test at 36 mo (36-39), the children were asked to place their hands flat on a table and to restrain themselves from eating a single M\&M candy from under a glass cup placed on the table in front of them. The children were instructed to delay eating until the research assistant rang a bell. The test was conducted over four distinct trials (using delays of 10, 20, 15, and $30 \mathrm{~s}$ ). Halfway through each trial delay, the experimenter lifted the bell but did not ring it. The children received a behavioral score for each trial ("behavior code") based on attempts to eat the candy before the bell rang. Coding ranged from 1 to $7(1=$ eats the candy before the bell is lifted, 2 = eats the candy after the bell is lifted, 3 = touches the candy before the bell is lifted, $4=$ touches the candy after the bell is lifted, $5=$ touches the bell or cup before the bell is lifted, 6 $=$ touches the bell or cup after the bell is lifted, and $7=$ waits for the bell to ring before touching cup or bell). In addition, for each trial, coders also recorded the ability of the children to wait for the M\&M (snack delay latency to eat, 1 = child keeps hands on mat during the entire time either before OR after the bell is lifted and 2 = child keeps hands on mat during the entire time before AND after the bell is lifted). This latter score ( 1 or 2 ) was then added to the behavioral code score (ranging from 1 to 7 ) to provide a single total performance score (ranging from 2 to 9 ) for each of the 4 trials. A "global cooperation score" rated the ability of the child to engage and complete the task $(0=$ the child is unwilling or unable to engage in the task; 1 = the child is unwilling or unable to complete the task because of feeling tired, angry, irritable, or sick, or does not have the capacity to understand the instructions; 2 = the child does all the trials but has comprehensional or motivational difficulties, or is passive or inhibited, and $3=$ the child understands the task well and participates). Only children with a global score of 2 and above were included in the analysis.

At 48 mo of age, children and their mothers were exposed to a 30-min test meal at approximately 10:30 AM, including different types of foods in preweighed portions (Frosted Flakes, sliced apple, muffin with chocolate drops, $3.25 \%$ milk, baked beans, croissant, cooked egg, cheddar cheese, All Bran, white bread, orange juice). Foods were chosen per the directions of a nutritionist to represent local habitual snack items and have similar colors (40). Mothers were instructed to offer a light breakfast to the participants at home beforehand, and not to share plates or influence the children's choices. Based on the nutritional content of each food and the amount eaten, we calculated the amount of fat, carbohydrates, and protein ingested (41-44).

\section{Statistical Methods}

Quantitative variables were described using mean \pm SE or median (25th percentile; 75th percentile), whereas categorical data were described using absolute $(n)$ and relative (\%) frequencies. To determine potential confounders, children in the IUGR and non-IUGR categories were compared with respect to several key variables including gender, smoking by the mother during gestation, age of the mother at the time of delivery, family income, the duration of exclusive breastfeeding, and the total duration of breastfeeding. The tests used were the Student's $t$-test or Mann-Whitney U test for quantitative variables, and $\chi^{2}$ tests for categorical variables.

Main analyses. Generalized estimating equation analysis was used for the snack delay task because this method is ideally suited for a series of trials with different time delays. Generalized estimating equation analysis is also well suited for within-subject repeated measures that are likely to be correlated, assuming measurements to be dependent within subjects and independent between subjects. This approach 
allows each observation from each individual to contribute to the analysis, preserving study power by using all available observations and avoiding listwise deletion of cases where a datum may be missing. This method of analysis allows the examination of the effects of each trial as well as the intragroup and intergroup differences over all the trials (45-47).

In testing hypothesis 1 , total performance scores on the snack delay test over the four trials served as the dependent measure, whereas gender, IUGR status (yes/no) and trial number (1-4) were used as independent factors. Where significant differences were found, post hoc testing was done using the least significant difference method.

For hypothesis $2 \mathrm{a}$, a simple linear regression analysis was performed to evaluate the influence of the snack delay performance at 36 mo of age on the amount of palatable fat eaten during the snack test at 48 mo of age. For this purpose, snack delay performance was defined as the mean total performance score across the four snack delay trials. Our aim was to investigate whether impulsive eating as measured by the snack delay test would predict intake of palatable fat 1 y later. This analysis was split by gender and adjusted for the 48-mo BMI (which could have an independent influence on food intake). We stratified data by gender in this study because our previous work (14) showed that women who had experienced IUGR in utero eat more carbohydrates in adulthood and have a higher waist-to-hip ratio than do women who did not experience IUGR.

For hypothesis $2 \mathrm{~b}$, hierarchical linear regressions were used to study the influence of both mean 36-mo snack delay performance and BWR on 36- and 48-mo BMI measures. In each case, for model 1, mean snack delay test performance was the only predictor variable, whereas model 2 included both the mean snack delay test performance and BWR. Statistical significance for all analyses was set at $P<0.05$.

\section{STATEMENT OF FINANCIAL SUPPORT}

This work was funded by the Canadian Institute of Health Research (CIHR). P.P.S. was funded by a CIHR fellowship grant (200610CFE-170826-164844).

\section{REFERENCES}

1. Forsén T, Eriksson J, Tuomilehto J, Reunanen A, Osmond C, Barker D. The fetal and childhood growth of persons who develop type 2 diabetes. Ann Intern Med 2000;133:176-82.

2. Ravelli AC, van der Meulen JH, Michels RP, et al. Glucose tolerance in adults after prenatal exposure to famine. Lancet 1998;351:173-7.

3. Law CM, Shiell AW, Newsome CA, et al. Fetal, infant, and childhood growth and adult blood pressure: a longitudinal study from birth to 22 years of age. Circulation 2002;105:1088-92.

4. Roseboom TJ, van der Meulen JH, Ravelli AC, et al. Blood pressure in adults after prenatal exposure to famine. J Hypertens 1999;17:325-30.

5. Barker DJ, Martyn CN, Osmond C, Hales CN, Fall CH. Growth in utero and serum cholesterol concentrations in adult life. BMJ 1993;307:1524-7.

6. Davies AA, Smith GD, Ben-Shlomo Y, Litchfield P. Low birth weight is associated with higher adult total cholesterol concentration in men: findings from an occupational cohort of 25,843 employees. Circulation 2004;110:1258-62.

7. Ravelli AC, van Der Meulen JH, Osmond C, Barker DJ, Bleker OP. Obesity at the age of $50 \mathrm{y}$ in men and women exposed to famine prenatally. Am J Clin Nutr 1999;70:811-6.

8. Ravelli GP, Stein ZA, Susser MW. Obesity in young men after famine exposure in utero and early infancy. N Engl J Med 1976;295:349-53.

9. Pilgaard K, Hammershaimb Mosbech T, Grunnet L, et al. Differential nongenetic impact of birth weight versus third-trimester growth velocity on glucose metabolism and magnetic resonance imaging abdominal obesity in young healthy twins. J Clin Endocrinol Metab 2011;96:2835-43.

10. Bettiol H, Sabbag Filho D, Haeffner LS, et al. Do intrauterine growth restriction and overweight at primary school age increase the risk of elevated body mass index in young adults? Braz J Med Biol Res 2007;40: 1237-43.

11. Forsén TJ, Eriksson JG, Osmond C, Barker DJ. The infant growth of boys who later develop coronary heart disease. Ann Med 2004;36:389-92.
12. Painter RC, de Rooij SR, Bossuyt PM, et al. Early onset of coronary artery disease after prenatal exposure to the Dutch famine. Am J Clin Nutr 2006;84:322-7; quiz 466-7.

13. Hales CN, Barker DJ. Type 2 (non-insulin-dependent) diabetes mellitus: the thrifty phenotype hypothesis. Diabetologia 1992;35:595-601.

14. Barbieri MA, Portella AK, Silveira PP, et al. Severe intrauterine growth restriction is associated with higher spontaneous carbohydrate intake in young women. Pediatr Res 2009;65:215-20.

15. Lussana F, Painter RC, Ocke MC, Buller HR, Bossuyt PM, Roseboom TJ. Prenatal exposure to the Dutch famine is associated with a preference for fatty foods and a more atherogenic lipid profile. Am J Clin Nutr 2008;88:1648-52.

16. Stein AD, Rundle A, Wada N, Goldbohm RA, Lumey LH. Associations of gestational exposure to famine with energy balance and macronutrient density of the diet at age 58 years differ according to the reference population used. J Nutr 2009;139:1555-61.

17. Gross LS, Li L, Ford ES, Liu S. Increased consumption of refined carbohydrates and the epidemic of type 2 diabetes in the United States: an ecologic assessment. Am J Clin Nutr 2004;79:774-9.

18. Oh K, Hu FB, Cho E, et al. Carbohydrate intake, glycemic index, glycemic load, and dietary fiber in relation to risk of stroke in women. Am J Epidemiol 2005;161:161-9.

19. Liu S, Willett WC, Stampfer MJ, et al. A prospective study of dietary glycemic load, carbohydrate intake, and risk of coronary heart disease in US women. Am J Clin Nutr 2000;71:1455-61.

20. Layman DK, Boileau RA, Erickson DJ, et al. A reduced ratio of dietary carbohydrate to protein improves body composition and blood lipid profiles during weight loss in adult women. J Nutr 2003;133:411-7.

21. Meaney MJ, Szyf M, Seckl JR. Epigenetic mechanisms of perinatal programming of hypothalamic-pituitary-adrenal function and health. Trends Mol Med 2007;13:269-77.

22. Levitt NS, Lambert EV, Woods D, Hales CN, Andrew R, Seckl JR. Impaired glucose tolerance and elevated blood pressure in low birth weight, nonobese, young south african adults: early programming of cortisol axis. J Clin Endocrinol Metab 2000;85:4611-8.

23. Plagemann A, Harder T, Brunn M, et al. Hypothalamic proopiomelanocortin promoter methylation becomes altered by early overfeeding: an epigenetic model of obesity and the metabolic syndrome. J Physiol (Lond) 2009;587(Pt 20):4963-76.

24. Diekhof EK, Gruber O. When desire collides with reason: functional interactions between anteroventral prefrontal cortex and nucleus accumbens underlie the human ability to resist impulsive desires. J Neurosci 2010;30:1488-93.

25. Dolan SL, Bechara A, Nathan PE. Executive dysfunction as a risk marker for substance abuse: the role of impulsive personality traits. Behav Sci Law 2008;26:799-822.

26. Leitner Y, Fattal-Valevski A, Geva R, et al. Neurodevelopmental outcome of children with intrauterine growth retardation: a longitudinal, 10-year prospective study. J Child Neurol 2007;22:580-7.

27. Geva R, Eshel R, Leitner Y, Fattal-Valevski A, Harel S. Memory functions of children born with asymmetric intrauterine growth restriction. Brain Res 2006;1117:186-94.

28. Franzek EJ, Sprangers N, Janssens AC, Van Duijn CM, Van De Wetering BJ. Prenatal exposure to the 1944-45 Dutch 'hunger winter' and addiction later in life. Addiction 2008;103:433-8.

29. Heinonen K, Räikkönen K, Pesonen AK, et al. Behavioural symptoms of attention deficit/hyperactivity disorder in preterm and term children born small and appropriate for gestational age: a longitudinal study. BMC Pediatr 2010;10:91.

30. Davis C. Attention-deficit/hyperactivity disorder: associations with overeating and obesity. Curr Psychiatry Rep 2010;12:389-95.

31. Liu Y, von Deneen KM, Kobeissy FH, Gold MS. Food addiction and obesity: evidence from bench to bedside. J Psychoactive Drugs 2010;42:133-45.

32. Dallman MF, Pecoraro N, Akana SF, et al. Chronic stress and obesity: a new view of "comfort food". Proc Natl Acad Sci USA 2003;100:11696-701.

33. de Rooij SR, Painter RC, Phillips DI, et al. Cortisol responses to psychological stress in adults after prenatal exposure to the Dutch famine. Psychoneuroendocrinology 2006;31:1257-65. 
34. de Rooij SR, Painter RC, Phillips DI, et al. Hypothalamic-pituitary-adrenal axis activity in adults who were prenatally exposed to the Dutch famine. Eur J Endocrinol 2006;155:153-60.

35. Kramer MS, Platt R, Yang H, McNamara H, Usher RH. Are all growthrestricted newborns created equal(ly)? Pediatrics 1999;103:599-602.

36. Kochanska G, Murray K, Jacques TY, Koenig AL, Vandegeest KA. Inhibitory control in young children and its role in emerging internalization. Child Dev 1996;67:490-507.

37. Golden M, Montare A, Bridger W. Verbal control of delay behavior in two year old boys as a function of social class. Child Dev 1977;48: $1107-1111$.

38. Campbell SB, Szumowski EK, Ewing LJ, Gluck DS, Breaux AM. A multidimensional assessment of parent-identified behavior problem toddlers. J Abnorm Child Psychol 1982;10:569-91.

39. Vaughn BE, Kopp CB, Krakow JB. The emergence and consolidation of self-control from eighteen to thirty months of age: normative trends and individual differences. Child Dev 1984;55:990-1004.

40. Addessi E, Galloway AT, Visalberghi E, Birch LL. Specific social influences on the acceptance of novel foods in 2-5-year-old children. Appetite 2005;45:264-71.
41. Westerterp-Plantenga MS, IJedema MJ, Wijckmans-Duijsens NE. The role of macronutrient selection in determining patterns of food intake in obese and non-obese women. Eur J Clin Nutr 1996;50:580-91.

42. Zandstra EH, Mathey MF, Graaf C, van Staveren WA. Short-term regulation of food intake in children, young adults and the elderly. Eur J Clin Nutr 2000;54:239-46.

43. Vozzo R, Wittert G, Cocchiaro C, et al. Similar effects of foods high in protein, carbohydrate and fat on subsequent spontaneous food intake in healthy individuals. Appetite 2003;40:101-7.

44. Boudville A, Bruce DG. Lack of meal intake compensation following nutritional supplements in hospitalised elderly women. Br J Nutr 2005;93: 879-84.

45. Zeger SL, Liang KY. Longitudinal data analysis for discrete and continuous outcomes. Biometrics 1986;42:121-30.

46. Liang K-Y, Zeger SL. Longitudinal data analysis using generalized linear models. Biometrika 1986;73:13-22.

47. Ballinger GA. Using generalized estimating equations for longitudinal data analysis. Organiz Res Met 2004;7:127-150.

48. Rothman L. Oh Canada! Too many children in poverty for too long. Paediatr Child Health 2007;12:661-665. 